\title{
Variable reluctance synchronous machines in saturated mode
}

\author{
Hleli Hanene ${ }^{1}$, Flah Aymen ${ }^{2}$, Tounsi Souhir ${ }^{3}$ \\ ${ }^{1,2}$ Lab PEESE, National School of Engineering of Gabes, University of Gabes, Tunisia \\ ${ }^{3}$ Innovent Systems for Energy Management (ISEM), Laboratory of Advanced Electronics Systems and Sustainable \\ Energy (ESSE), Sfax University, Tunisia
}

\begin{tabular}{|c|c|}
\hline Article Info & ABSTRACT \\
\hline Article history: & \multirow{9}{*}{$\begin{array}{l}\text { Electric vehicle seems largely based on electrical machines. Finding the best } \\
\text { motor type seems be important for having more perfromances and a transport } \\
\text { system robustness. In this work, we present an analytical model of the } \\
\text { synchronous machine with variable reluctances in linear and saturated } \\
\text { modes. The angular position of the rotor }(\theta) \text { and the phase current (i) will be } \\
\text { used as parameters. The analytical model of this machine will allow us to } \\
\text { determinate its magnetic characteristics such inductors, magnetic flux and } \\
\text { electromagnetic torque. The results obtained by the analytical model are } \\
\text { compared with those obtained by the finite element method. So, basing on } \\
\text { MATLAB/Simulink tool and by working with finite element method, these } \\
\text { results are depicted and the paper objective is illustrated. }\end{array}$} \\
\hline Received Jun 10, 2020 & \\
\hline Revised Mar 22,2021 & \\
\hline Revised Mar 22, 2021 & \\
\hline Accepted Apr 30, 2021 & \\
\hline Keywords: & \\
\hline Models & \\
\hline Saturated regime & \\
\hline Synchronous machine & \\
\hline
\end{tabular}

This is an open access article under the CC BY-SA license.

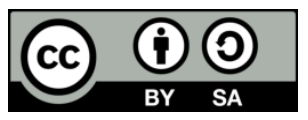

Corresponding Author:

Hleli Hanene

Lab PEESE

National School of Engineering of Gabes

University of Gabes, Tunisia

Email: hleli.hanene@yahoo.fr

\section{INTRODUCTION}

Variable reluctance machines, because of their broad power range, are commonly used nowadays. For properly understand these types of motors, we must know their origin. The first double constructs seem to have emerged in the 1920s. They were the first systems to appear. A research that explains the physical theory of force generation in variable reluctance machines, which has often preceded the first implementations, was published in 1927 [1], [2].

In 1930, synchronous motors with variable reluctance started to be known. It was used for particular applications that needed an accurate and realistic speed. The electromagnetic arrangement didn't make for a high enough salient ratio. In the 1960s, there was renewed interest in these types of machines [3]. And there are the variable rotor reluctance synchronous motors [4]. The aim of developing flux barriers and axially rolling rotors was to increase the salience ratio and thus the power and efficiency. There was also renewed interest in variable-reluctance motors with either a wide teeth and high torque: these engines appeared to be well suited to the realization of direct reduced motors size, such as those used in electric vehicle tires. The term "switched reluctance motor" first emerged in 1969 for the selfcommutated double relieved variable reluctance motor [5]. It is now the term used to describe these devices in international scientific literature.

Today's uses include variable-speed industrial drives, as well as future applications such as automobile and electrical appliance components and turbine starter-alternators (aeronautics). This type of system is very important to study and necessitates knowledge of motor parameters such as resistance, inductance, and internal flow. As a consequence, in this article, we attempt to present two methods for estimating the efficiency of an electromagnetic actuator, which may be empirical, theoretical, or experimental. a) the finite element method (MEF) is a numerical approximation method used to solve static and dynamic boundary problems, b) the analytical models contain a series of 
mathematical formulas that interpret the actuator's function as precisely as possible and c) the experimental procedure: This is a useful approach, although it is not always feasible [6].

We have chosen the analytical approach because we want a model that is fast, feasible, and reliable. Nonetheless, a finite element model would be needed. It is required for validation even if it is not used for model creation. Furthermore, after dimensional optimization, it is proposed that the results be tested using a finite element model. These methods help one to evaluate the magnetic properties of the engine, such as flux, current, and inductance variations [7].

This work is described in four principal parts, the first one deal with the geometry and dimensions of our model, the second part concerns the study of the machine in a linear regime and the third is the study of the machine in saturated regime. One of these two parts will include modeling of the machine by finite element and by analytical method. Finally, a comparative study of the results will be presented and discussed in a fourth part.

\section{MOTOR STRUCTURE}

\subsection{Topology}

Synchronous motors with variable reluctance can be regular or irregular. A regular motor is one whose poles are symmetrical around the central lines equally spaced around rotor and stator respectively. The variable reluctance synchronous machine can be designed by several numbers of phases. In short, it can be classified depending on the number of phases (single phase, three-phase) or the number of poles $(6 / 4,8 / 6)$. Our research is focused on the case of a Three-phase machine. Each phase contains two coils connected in such a way that their flows are additive [8], [9].

\subsection{Motor operating strategy}

The operation is like a series of electrical pulses applied to the coils of each phase in an alternating manner. They start when two rotor poles become aligned with a pair of stator poles. The duration of these electrical pulses can be adjusted in order to improve the characteristics of the machine [10].

\subsection{Design and geometry}

The geometry of a variable reluctance synchronous machine is based on a set of parameters that are reference $\mathrm{d}$ in (1). Figure 1 shows the design and the geometry of this machine.

$$
\mathrm{c}_{\mathrm{c}}=\frac{2 \times \mathrm{p}}{24 \times \mathrm{n}}
$$

In our case, $\mathrm{n}$ is set to one.

$$
\begin{aligned}
& \mathrm{N}_{\mathrm{ds}}=3 \times \mathrm{n} \\
& \mathrm{N}_{\mathrm{dis}}=3 \times \mathrm{n} \\
& \mathrm{N}_{\mathrm{dr}}=4 \times \mathrm{n} \\
& \mathrm{N}_{\mathrm{sl}}=2 \times 3 \times \mathrm{n}
\end{aligned}
$$

To receive triangular inductances moved by an amount $\theta$ to $2 . / 3$, the following conditions must be met, a) the stator teeth's angular opening is equivalent to the rotor teeth's angular opening, and b) the angular opening of the gap between stator teeth is $5 / 3$ of a size of a stator tooth [11], [12].

We have:

$$
\mathrm{A}_{\text {dent1 }}=3 \times \mathrm{C}_{\mathrm{c}}
$$

$$
\mathrm{A}_{\mathrm{enc}}=\mathrm{C}_{\mathrm{c}}
$$

$\mathrm{A}_{\mathrm{den} 2}=3 \times \mathrm{C}_{\mathrm{c}}$

$\mathrm{A}_{\mathrm{dr}}=3 \times \mathrm{C}_{\mathrm{c}}$

$\mathrm{A}_{\mathrm{dentr}}=\frac{2 \times \pi-\mathrm{N}_{\mathrm{dr}} \times \mathrm{A}_{\mathrm{dr}}}{\mathrm{N}_{\mathrm{dr}}}$ 


$$
\begin{aligned}
& \mathrm{H}_{\mathrm{cs}}=\frac{\mathrm{B}_{\mathrm{d}} \times \mathrm{S}_{\mathrm{d}}}{2 \times \mathrm{B}_{\mathrm{cs}} \times \mathrm{L}_{\mathrm{m}}} \\
& \mathrm{H}_{\mathrm{cr}}=\frac{\mathrm{B}_{\mathrm{e}} \times \mathrm{S}_{\mathrm{d}}}{2 \times \mathrm{B}_{\mathrm{cs}} \times \mathrm{L}_{\mathrm{m}}} \\
& \mathrm{H}_{\mathrm{d}}=\frac{\mathrm{N}_{\mathrm{sph}} \times \mathrm{I}_{\mathrm{dim}}}{\delta \times \mathrm{L}_{\mathrm{ens}} \times \mathrm{K}_{\mathrm{f}}}
\end{aligned}
$$

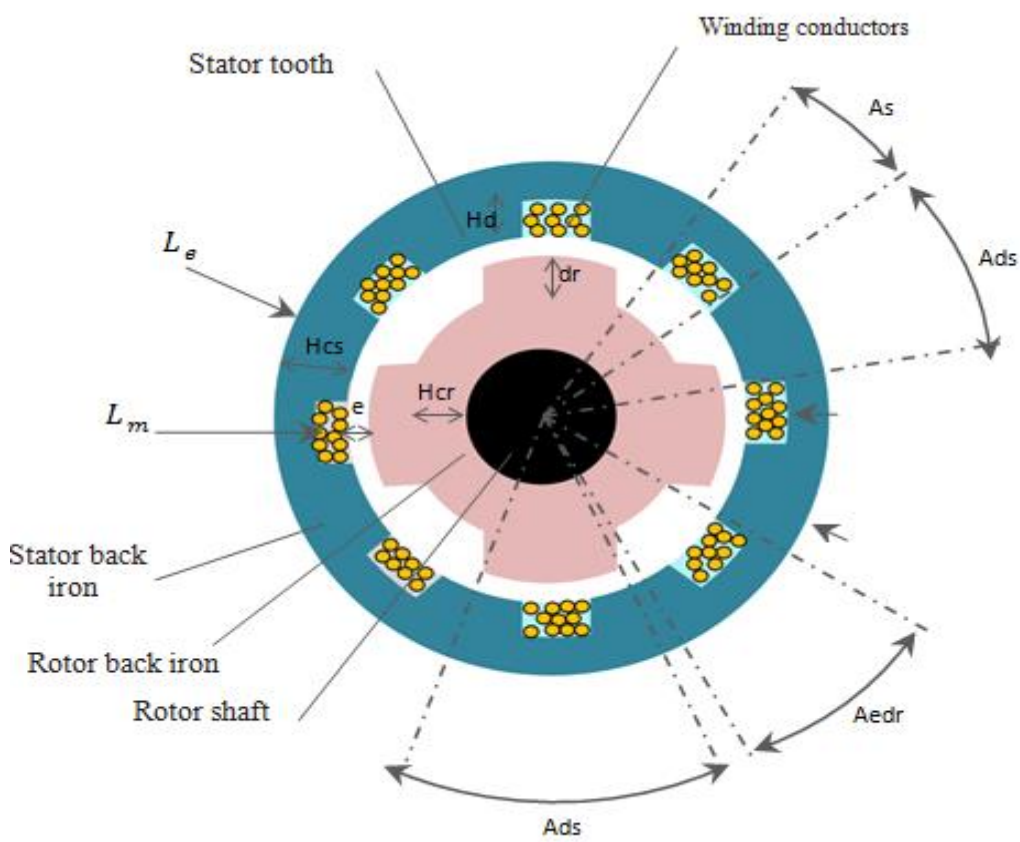

Figure 1. Prototype parameters

\section{THE MOTOR IS MODELED USING FINITE ELEMENTS}

The finite element theory derives from the work of Fermat and Bernouilli (1743), as well as Galerkin's method based on approximation equations in Hilbert spaces. Robert Courant implemented the variety theorem of local support functions in 1943, setting the stage for the subdivision of a given domain into "elements". Even so, it is still with the advancement of computing that these works seek use, with the groundbreaking works of Zienckiewiz and Argyris establishing the method in 1960.The contribution of the matrix measurement, implemented by an unknown civil engineer, is what leads to the method's performance and strength. The method then experienced a rapid growth, aided by advances in computer science.

Today, finite elements are a big instrument that is inevitable in mechanics (fluids and solids, relations, and structures) and valid in many fields including boundary problems, such as financial mathematics or electromagnetismThere are numerous industrial codes (solvers) available, which are usually paired with software or ss (CAD) software [13]. For this work we use the software finite element method magnetics (FEMM)

\subsection{Create model}

The motor was a three-phase, two-pole pair $(\mathrm{p}=2)$ design. Four teeth make up the rotor. The coils are concentrated and the holes are straight. This speed up the process of automating them and integrating them into a block. The winding is a tooth set enclosed by a coil. The motor's torque is caused by the difference in salience along the air distance. We use low-height teeth to reduce the impact of the rotor's variation in inertia during rotation [14]. The process parameters are shown in the Table 1. 
Table 1. Dimensions of the prototype

\begin{tabular}{ll}
\hline Symbols & Dimensions \\
\hline $\mathrm{Lm}$ & $500 \mathrm{~mm}$ \\
$\mathrm{E}$ & $2.5 \mathrm{~mm}$ \\
$\mathrm{Ra}$ & $40.121 \mathrm{~mm}$ \\
Dst & $300.000 \mathrm{~mm}$ \\
Nsph & 550 \\
$\mathrm{hcr}$ & $50.279 \mathrm{~mm}$ \\
$\mathrm{hcs}$ & $31,425 \mathrm{~mm}$ \\
$\mathrm{hd}$ & $46,039 \mathrm{~mm}$ \\
$\mathrm{dr}$ & $60.27 \mathrm{~mm}$ \\
Ndrp & 4.000 \\
Ndsp & 3.000 \\
Ndsi & 3.000 \\
Adent 1 & $45.000^{\circ}$ \\
Adent2 & $45.000^{\circ}$ \\
Aenc & $15.000^{\circ}$ \\
Adentr 1 & $45.000^{\circ}$ \\
\hline
\end{tabular}

\subsection{Materials}

The realization of a high-performance machine has always been our goal. Three types of materials were used which are:

a. Copper for coils: Copper is not magnetic or is just mildly magnetic (not large enough to see under usual circumstances), but it interacts with magnets.

b. Pure iron for the stator and the rotor: We notice the existence of two parts. A linear part that corresponds to the linear mode. A non-linear part that corresponds to the sattured mode [15], [16].

\subsection{Generate mesh and run FEA}

A linear mesh of 17454 components has been used. Figure 2 demonstrates the flow lines and flux density for various values of the flow path and flux density.
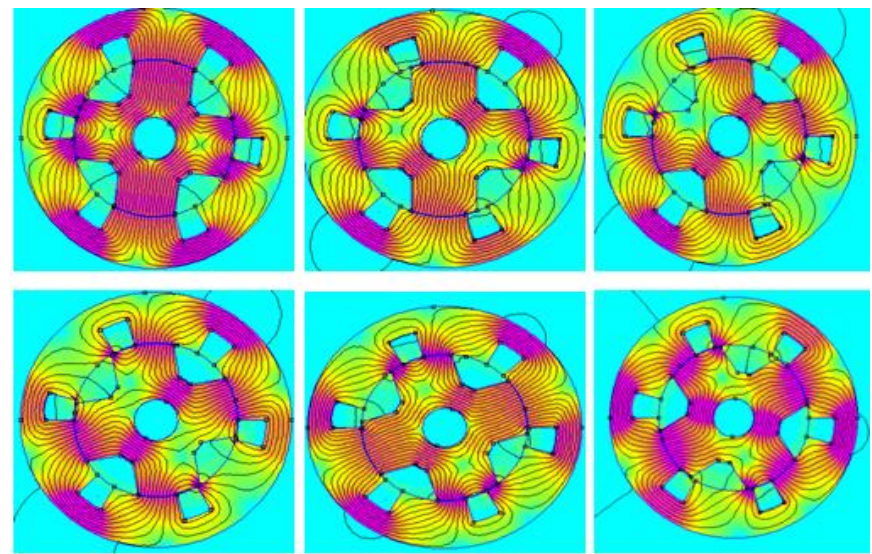

Figure 2. Induction and flow lines

\subsection{Analysis results}

\subsubsection{Evolution of the inductances in linear mode}

The inductance is estimated as follows for each value of $\theta$ ca be visualized as it is in Figure 3 . The cycle presented in the previous figure is an idealized cycle, the variation of the inductance is linear. The duration of the complete alignment period is related to the relative geometry of the teeth and may be missing in the case of an identical width of the two teeth. The slopes of growth and decay of the inductors are important for the production of the torque. It should also be noted that the value of the inductance is never zero, even in the non-aligned position, there is an inductance between the stator tooth and the rotor yoke $\mathrm{L}_{\mathrm{min}}$. 


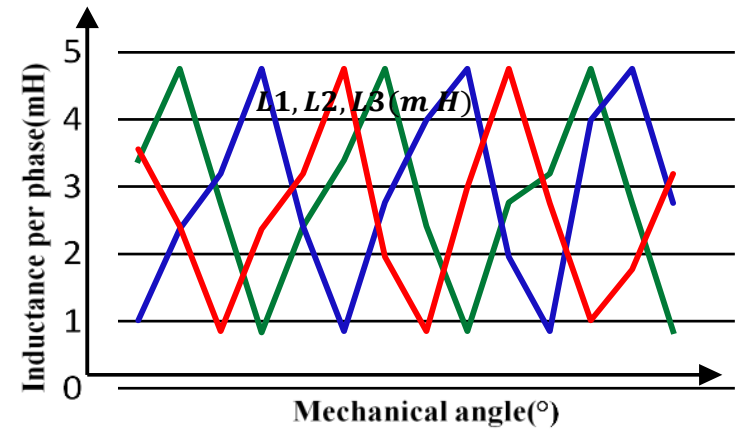

Figure 3. The evolution of inductances as a function of mechanical angles (Linear mode)

\subsubsection{Evolution of the inductances in satturated mode}

The evolution of the inductance variable in the saturated mode can be sown in Figure $\theta 0-\theta 1$ : the linear growth period of the inductance, when the rotor tooth is beginning to align with the stator tooth; in $\theta 1$ the rotor tooth is completely aligned and the inductance reaches the maximum value Lmax; the torque produced in this zone is positive with respect to the direction of rotation. $\theta 1-\theta 2$ : period of complete alignment of the two teeth; on this region the inductance remains at the maximum value and there is no production of torque. $\theta 2-\theta 3$ : the misalignment period, with the rotor tooth away from the aligned position; the variation of inductance of the maximum value Lmax up to the non-alignment value Lmin produces a negative torque in the direction of rotation chosen as reference. $\theta 3$ : the inductance value remains unchanged. Lmin and consequently there is no production of torque.

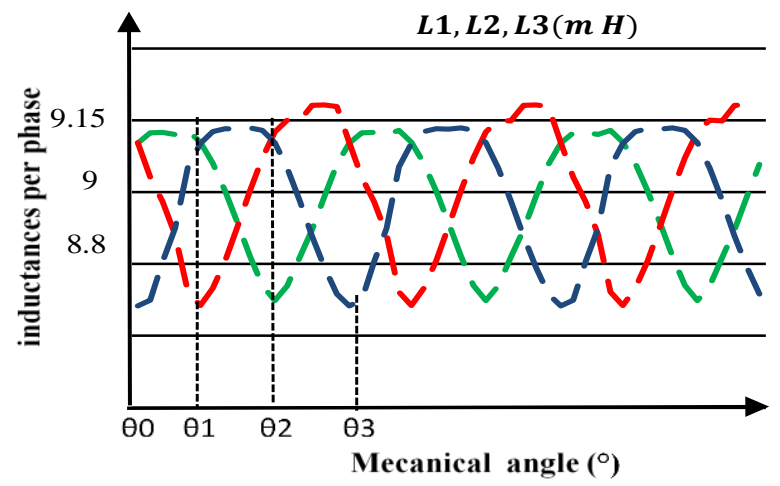

Figure 4. Evolution of the inductances in function of the mechanical angles (satturated mode)

\section{ANALYTICAL MODEL}

\subsection{Linear mode}

The motor's phase inductances are expressed by the (14) instead from (15) and (16). These (14) to (16) show all the studied parameters and gives the mathematical relationship.

$$
\begin{aligned}
& \text { if } 0 \leq \theta \leq A_{\text {dent1 }} \\
& L_{1}=\mathrm{L}_{\mathrm{C} 0}+\mathrm{C}_{i} \times \theta \\
& \text { if } A_{\text {dent } 1} \leq \theta \leq 2 \times \mathrm{A}_{\text {dent } 1} \\
& L_{1}=\mathrm{L}_{\mathrm{C} 0}+\mathrm{C}_{i} \times \mathrm{A}_{\text {dent } 1}-\mathrm{C}_{i} \times \dot{\theta} \\
& \text { if } \frac{2}{3} \times 2 \times \mathrm{A}_{\text {dent } 1} \leq \theta \leq \frac{7}{3} \times \mathrm{A}_{\text {dent } 1}, \\
& L_{2}=\mathrm{L}_{\mathrm{C} 0}+\mathrm{C}_{i} \times\left(\theta-\frac{2}{3} \times 2 \times \mathrm{A}_{\text {dent } 1}\right)^{\prime}
\end{aligned}
$$


if $\frac{7}{3} \times \mathrm{A}_{\mathrm{dent} 1} \leq \theta \leq \frac{10}{3} \times \mathrm{A}_{\mathrm{dent} 1}$;

$L_{2}=\mathrm{L}_{\mathrm{C} 0}+\mathrm{C}_{i} \times \mathrm{A}_{\mathrm{dent} 1}-\mathrm{C}_{i} \times\left(\theta-\frac{7 \times \mathrm{A}_{\mathrm{dent} 1}}{3}\right)^{\prime}$

if $\frac{4}{3} \times 2 \times \mathrm{A}_{\mathrm{dent} 1} \leq \theta \leq \frac{11}{3} \times \mathrm{A}_{\mathrm{dent} 1}$;

$L_{3}=\mathrm{L}_{\mathrm{c} 0}+\mathrm{C}_{i} \times\left(\theta-\frac{4}{3} \times 2 \times \mathrm{A}_{\mathrm{dent} 1}\right)$

if $\frac{11}{3} \times \mathrm{A}_{\text {dent1 }} \leq \theta \leq \frac{14}{3} \times \mathrm{A}_{\text {dent1 }}$

$L_{3}=\mathrm{L}_{\mathrm{C} 0}+\mathrm{C}_{i} \times \mathrm{A}_{\mathrm{dent} 1}-\mathrm{C}_{i} \times\left(\theta-\frac{11 \times \mathrm{A}_{\mathrm{dent} 1}}{2}\right)^{\prime}$

Where:

$$
\begin{aligned}
& C_{i}=\frac{N_{\mathrm{dsp}}}{2} \times \frac{\left(\mu_{0} \times \frac{D_{\mathrm{st}}}{2} \times \mathrm{L}_{m}\right) \times\left(\frac{N_{\mathrm{sph}}}{\left(\frac{N_{\mathrm{dsp}}}{2}\right)}\right)^{2}}{2 \times \mathrm{e}} . \\
& L_{\mathrm{c} 1}=\frac{N_{\mathrm{dsp}}}{2} \times \frac{\left(\mu_{0} \times \mathrm{H}_{d} \times \mathrm{L}_{m}\right) \times\left(\frac{N_{\mathrm{sph}}}{\left(\frac{N_{\mathrm{dsp}}}{2}\right)}\right)^{2}}{L_{\mathrm{enc}}} .
\end{aligned}
$$

The variation of the inductances according to the rotor angle is given by the Figure 5 .

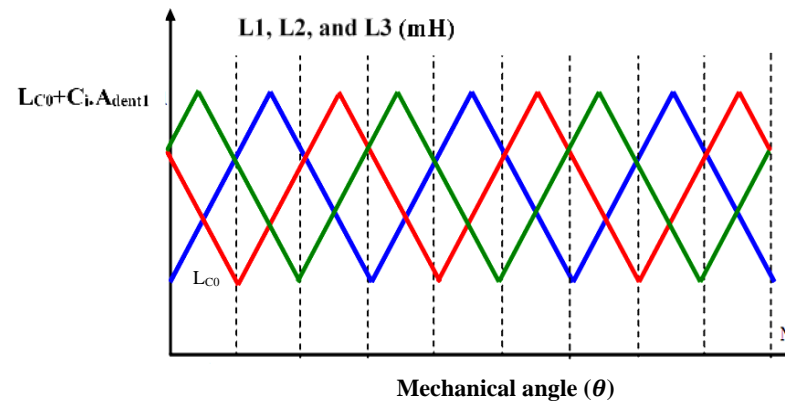

Figure 5. Evolution of the inductances in linear mode

\subsection{Saturated mode}

The synchronous variable reluctance machine construction is particular by the double saliency of the motor poles. The characteristics of the machine are generally nonlinear as they often operate in the saturated region of the magnetization characteristics. Then, its operation can't be represented by linearized analytical models, such as the synchronous and induction motor. Therefore, a nonlinear model taking into account the motor magnetization characteristic is mandatory in order to correctly represent our machine. This part will present the design and implementation of a nonlinear model of the machine to be used in the Simulink environment. The proposed model is implemented as a Simulink block containing six subsystems. It is based on two main inputs which are current and rotor positions. The output studied is the three-phase inductances L1, L2 and L3.

The saturation is calculated considering the induction in stator tooth can't achieve the saturation value of the iron B-H curve[17], [18]. The saturation values of inductances are measured using the linear model and the (19) to (22).

$$
\mathrm{f}_{\text {satt }}=\mathrm{f}_{0}+\mathrm{ds} \times \mathrm{B}_{\mathrm{e}}=\mathrm{f}_{0}+\frac{\mathrm{D}_{\text {st }}}{2} \times \mathrm{L}_{\mathrm{m}} \times \mathrm{B}_{\mathrm{e}} \times \mathrm{d} \theta
$$




$$
\begin{aligned}
& \mathrm{f}_{\text {satt }}=\left(\mathrm{L}_{\mathrm{co}}+\mathrm{L}(\theta)\right) \times \mathrm{I}_{\text {satt }} \\
& \mathrm{B}_{\text {dsatt }}=1.6 \\
& \mathrm{~B}_{\mathrm{dsatt}} \times \mathrm{S}_{\mathrm{ds}}=\mathrm{ds} \times \mathrm{B}_{\mathrm{e}}
\end{aligned}
$$

This magnetization characteristic can also be obtained by a finite element calculation if we know the geometry of the machine.The experimental tests carried out on the actual machine.An example of an application using the developed block (with specific models of a 6/4 motor) [19].

\subsection{Simulink model}

The global model of the power chain is composed of a speed and current regulator, a converter model and a dynamic equation model. The diagram in Figure 6, shows all the needed blocas and present haw each bloc is connected to the other. Here, the reference speed is equal to $80 \mathrm{Km}$.

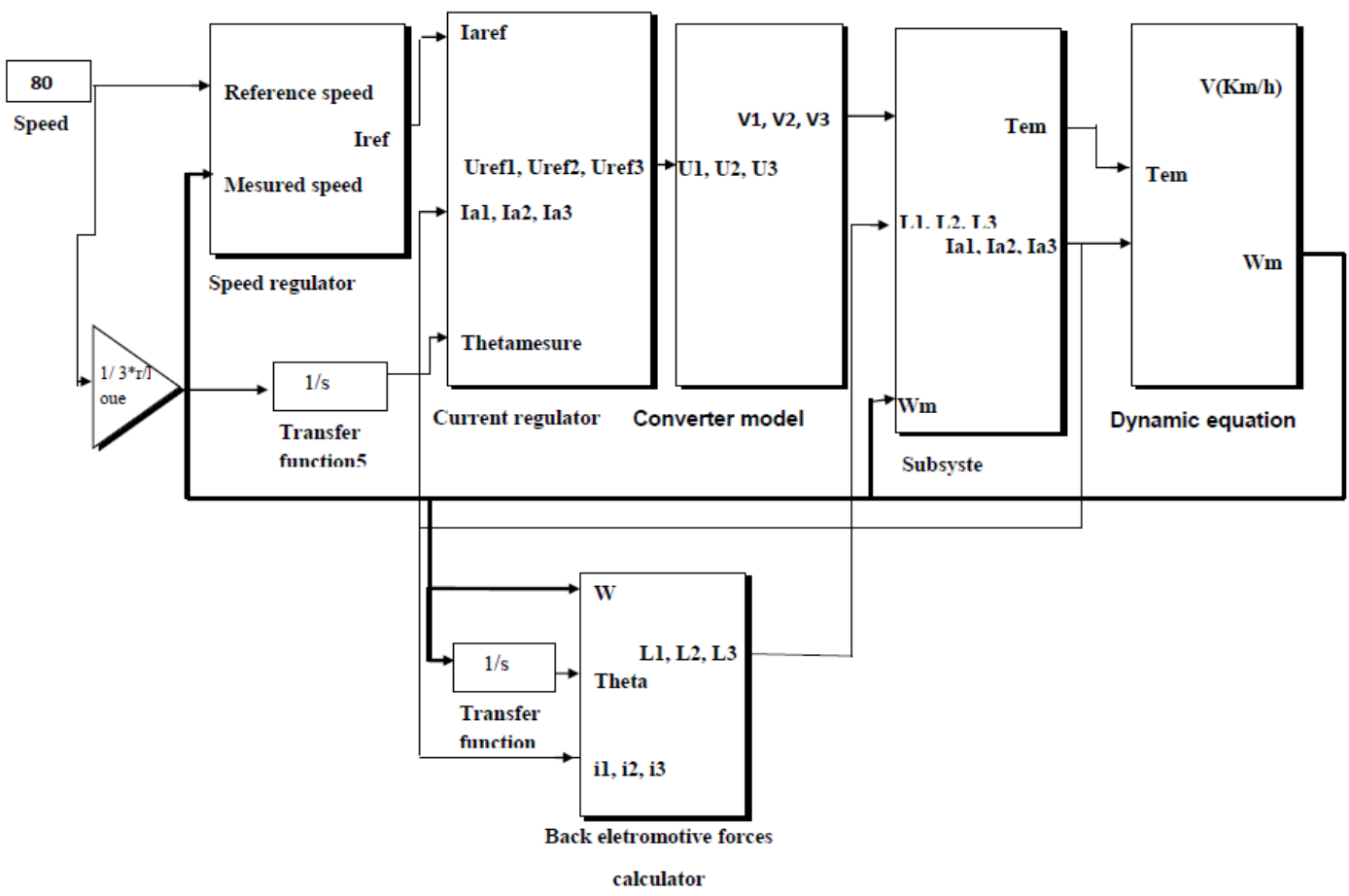

Figure 6. Global model of the power chain

\subsubsection{Speed regulator}

To provide the amplitude of the reference current while reducing the error between the reference and response speeds, a (PID) regulator form is used. This is for controlling the motor speed and supervising this variable in order to control the vehicle speed and acceleration.

\subsubsection{Model of current regulator}

Present regulators are used to change the strength and form of currents while minimizing torque fluctuation to reduce the disparity between the reference and reaction speeds. Currents can be separated into two parts: a direct current element and a component that differs in phase conflict with inductances. To obtain an optimized form of the motor torque for a constant reference rpm, two currents are positive and one is negative. 


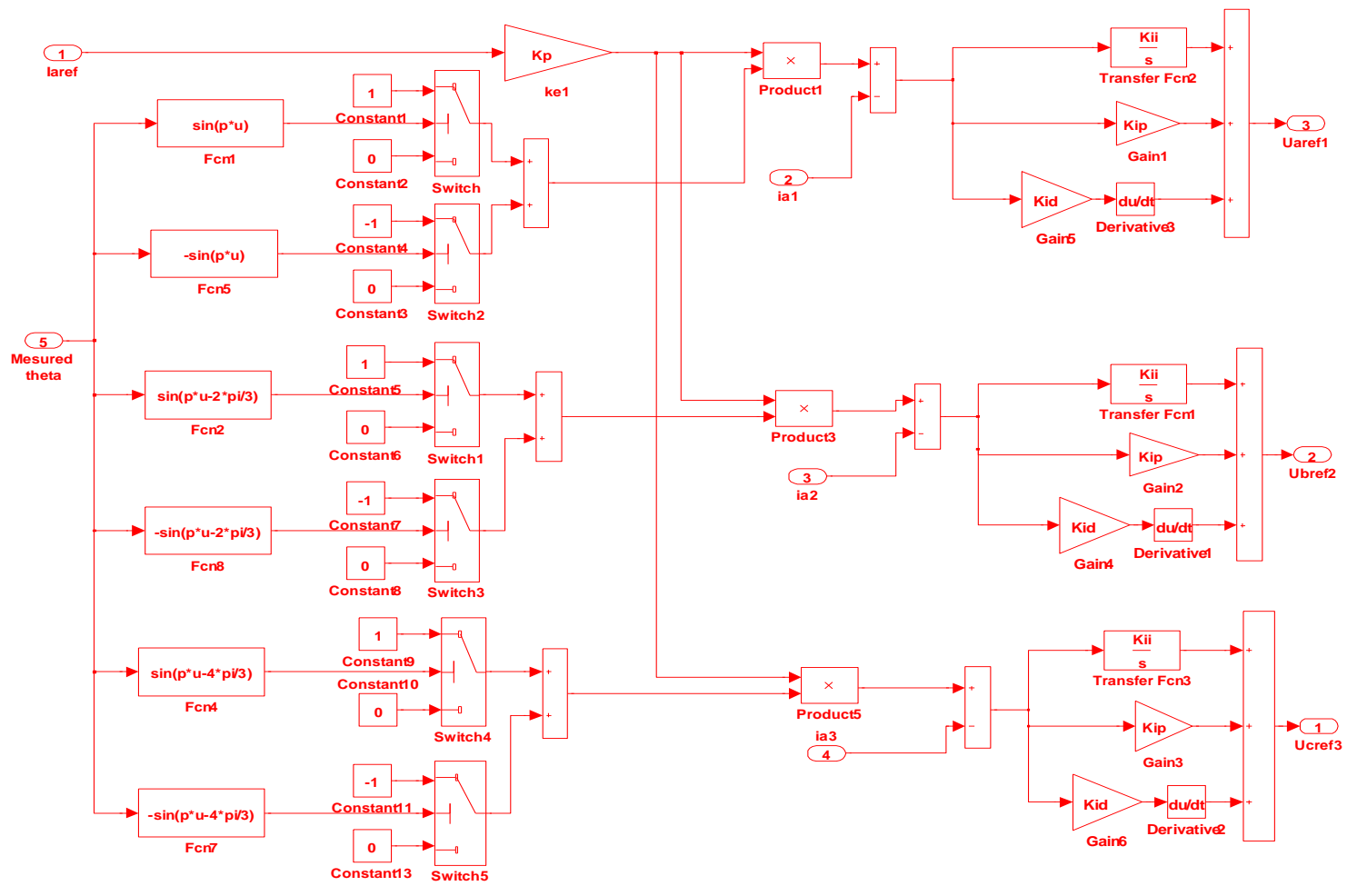

Figure 7. Model of current regulator

Errors among calculated and current and voltage modes are performed to illustrate the use and verify model action. This specific model produces very accurate results because it is suitable for a specific machine using measured or calculated data reference currents attack two proportional-integral-derivative regulators type to provide the two reference voltages required for generating the two control signals of the IGBT transistors. The use of genetic algorithms reduces torque ripple and, as a result, the fluctuation of response speed. Figure 7 illustrates the Simulink model of the new regulators.

\subsubsection{Converter model}

The converter's estimated model is built on the manipulation of three voltage levels by a triangular signal. To replicate the evolution of the three phases supply voltages, the outputs of the three comparators attack two hysteresis depending from the value of the DC bus voltage Udc and 0 [20], [21] and [22].

\subsubsection{Motor model}

The voltages of the motor phases are represented by the (23) to (25).

$$
\begin{aligned}
& \mathrm{V}_{1}=\mathrm{R} \times \mathrm{i}_{1}+\frac{\mathrm{d}\left(\mathrm{L}_{1} \times \mathrm{i}_{1}\right)}{\mathrm{dt}} \\
& \mathrm{V}_{2}=\mathrm{R} \times \mathrm{i}_{2}+\frac{\mathrm{d}\left(\mathrm{L}_{2} \times \mathrm{i}_{2}\right)}{\mathrm{dt}} \\
& \mathrm{V}_{3}=\mathrm{R} \times \mathrm{i}_{3}+\frac{\mathrm{d}\left(\mathrm{L}_{3} \times \mathrm{i}_{3}\right)}{\mathrm{dt}}
\end{aligned}
$$

Where $\mathrm{R}$ is the phase resistance, L1, L2 and L3 are respectively the inductance of the phase 1, 2 and 3 and i1, i2 and 13 are respectively the current of the phase 1,2 and 3.

The resistance is measured for a temperature of $90^{\circ} \mathrm{C}$, taking into account an engineered cooling mechanism that is automated to keep the temperature of copper constant at this value.

The (26) expresses the torque generated by the engine [23]-[25]. 


$$
\mathrm{T}_{\mathrm{m}}=\frac{1}{\Omega} \frac{\mathrm{d}\left(\frac{1}{2} \times\left(\mathrm{L}_{1} \times \mathrm{i}_{1}^{2}+\mathrm{L}_{2} \times \mathrm{i}_{2}^{2}+\mathrm{L}_{3} \times \mathrm{i}_{3}^{2}\right)\right)}{\mathrm{dt}}
$$

The electrical-mechanical motor theory is implemented in the MATLAB/Simulink simulation framework. The basic interaction of mechanics is used to obtain the (27).

$$
M_{v} \times R_{\text {roue }} \times \frac{d V}{d t}=r \times T_{m}-T_{R}(V)
$$

\subsubsection{Inductane calculator}

The inductances model is implanted under MATLAB/Simulink environnement according to Figure 8. It contains all the needed inputs and show clearly the output parameters as the three current waves. The inductances L1, L2 and L3 depend on the constant values of the inductances Lc0, Lc1 and Lc3 which are.

$$
\begin{aligned}
& \mathrm{L}_{C 0}=\mathrm{N}_{\mathrm{dsp}} / \begin{array}{l}
3 \times 4 \times \pi \times[10]^{7} \times\left(\mathrm{N}_{\mathrm{sph}} /\left(\mathrm{N}_{\mathrm{dsp}} / 3\right)\right)^{2} \\
\times\left(\left(\mathrm{h}_{\mathrm{d}} \times \mathrm{L}_{\mathrm{m}}\right) / \mathrm{L}_{\mathrm{enc}}\right)
\end{array} \\
& \mathrm{L}_{\mathrm{C} 1}=\mathrm{L}_{\mathrm{C} 0}
\end{aligned}
$$
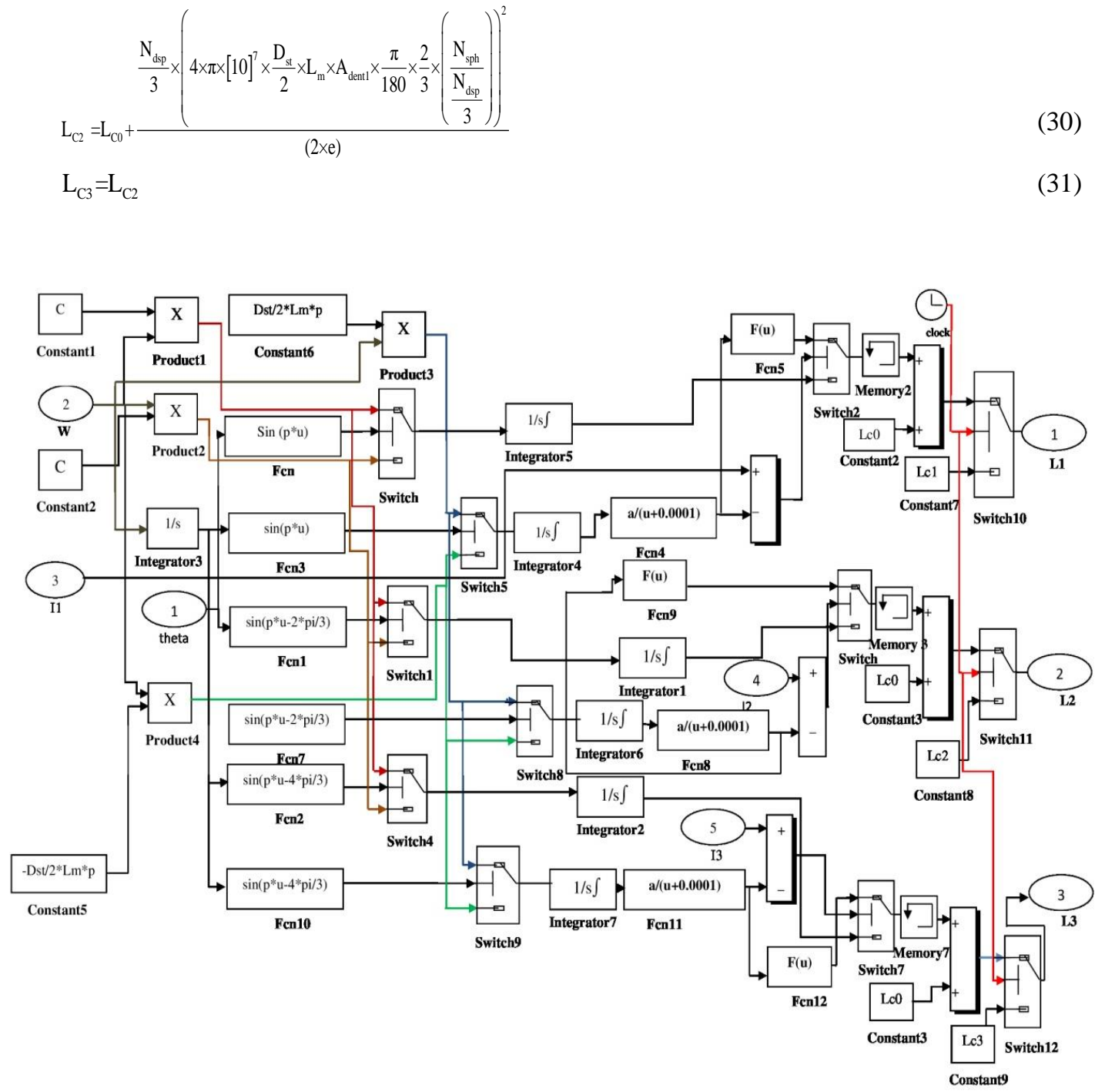

Figure 8. The inductances' Simulink model 


\subsubsection{Simulation results}

For the simulation test we have based on this real motor caracterestics, presented in Table 2. The variation of the inductances according to the rotor angle is given by Figure 9. The curves of variations of the inductances for the linear mode are given by the Figure 10. For the linear regime, we notice that the form of the inductance is triangular and that varies between two extreme values Lmin and Lmax. We note also that the percentage of error between the analytic model and the finite model does not exceed 5\%. Then our model is validated for the case of a linear regime. For the saturated regime, the inductance curves are illustrated in the Figure 11.

Table 2. Motor paramaters

\begin{tabular}{|c|c|c|}
\hline Parameters & Values & Units \\
\hline $\mathrm{R}_{\text {wheel }}$ & 0.26 & $\mathrm{~m}$ \\
\hline Udc & 4.1 & $\mathrm{~V}$ \\
\hline $\mathrm{Mv}$ & 1000 & $\mathrm{Kg}$ \\
\hline $\mathrm{r}$ & 3.6 & l \\
\hline $\mathrm{R}_{\text {batt }}$ & 0.01 & $\mathrm{~m}$ \\
\hline $\mathrm{Bcs}$ & 1.6 & $\mathrm{~T}$ \\
\hline $\mathrm{Bd}$ & 0.7 & $\mathrm{~T}$ \\
\hline Mcs & 105.230 & $\mathrm{Kg}$ \\
\hline Mds & 331.742 & $\mathrm{Kg}$ \\
\hline $\mathrm{Ci}$ & $0.072 / 1000$ & l \\
\hline Adent 1 & 45 & $\circ$ \\
\hline $\mathrm{Lm}$ & $500 / 1000$ & $\mathrm{~mm}$ \\
\hline Dst & $300 / 1000$ & $\mathrm{~mm}$ \\
\hline sdp & 3 & \\
\hline $\mathrm{e}$ & $2 / 1000$ & $\mathrm{~mm}$ \\
\hline Sds & Adent $1 *$ pi/ $180 *(\mathrm{Dst} / 2) * \mathrm{Lm}$ & $\mathrm{mm}^{2}$ \\
\hline Lmin & $32.318 / 1000$ & $\mathrm{~mm}$ \\
\hline Nsph & 546 & coil \\
\hline $\mathrm{a}$ & $2 * 1.6 * \mathrm{Sds} * \mathrm{e} /(4 * \mathrm{pi} / 10000000 * \mathrm{Nsph})$ & / \\
\hline In & 275 & A \\
\hline Aenc & 15 & $\circ$ \\
\hline rcu & $0.0176 * 0.000001$ & Ohm.m \\
\hline $\mathrm{kr}$ & 0.65 & / \\
\hline delta & 6 & $\mathrm{~A} / \mathrm{mm}^{2}$ \\
\hline
\end{tabular}

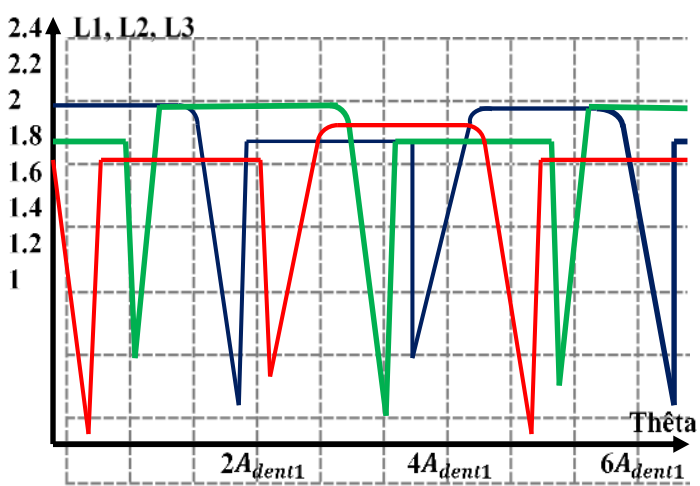

Figure 9. Inductances variation in saturated mode

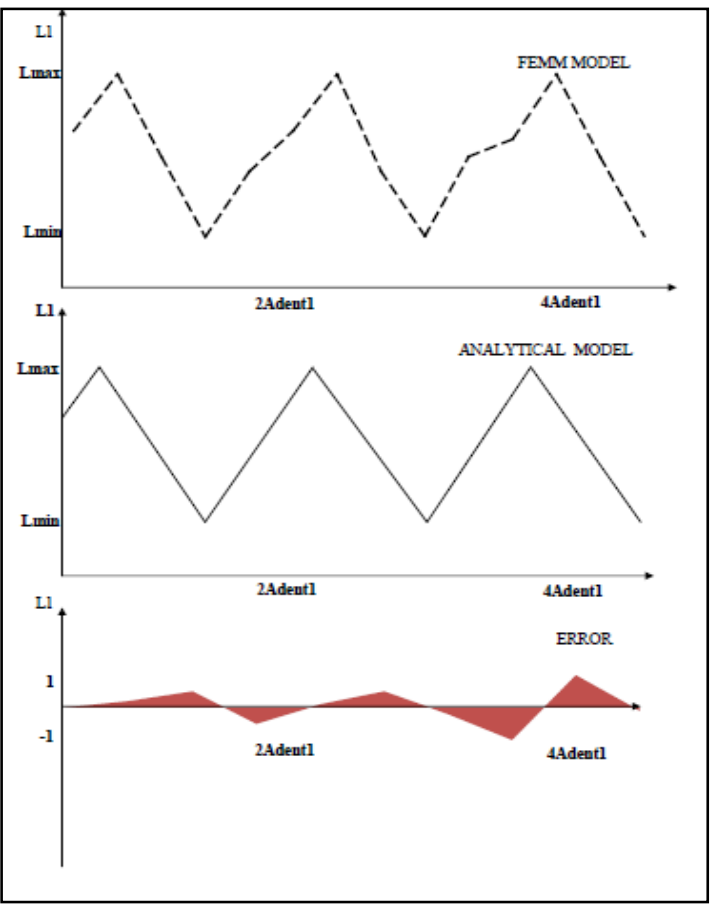

Figure 10. Inductances variation in linear mode

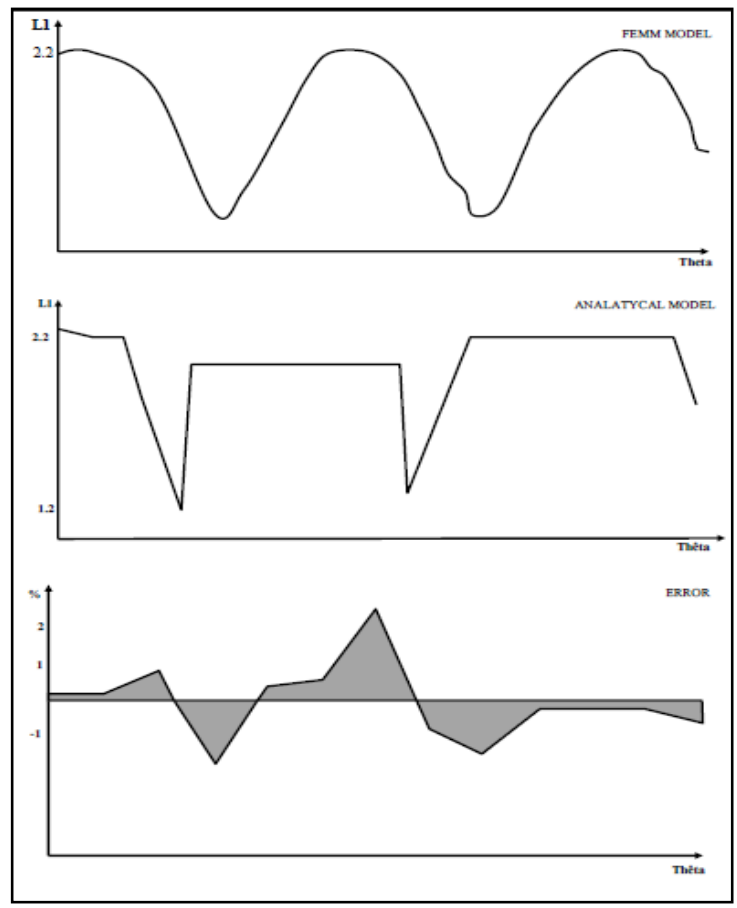

Figure 11. Inductances variation in saturated mode 


\section{CONCLUSION}

The machine's finite element modeling is discussed in the first section. The simulation techniques are presented first, followed by the estimation of the model's parameters. The finite element model is used to validate the empirical model by studying the variance of stator inductances for various rotor positions.

The FEMM 4.2 software is used to perform the finite element analysis. The lengthy computation times and computational resources used to perform this method of investigation limit the number of cases that can be examined. The analytical model is the focus of the second section. The evolution of these inductances has been supported by this model. Finally, we contrasted the empirical and finite element models. We discovered that the error is not particularly high. The maximum error is around $4 \%$, which is appropriate in our situation.

\section{REFERENCES}

[1] J. Wells, H. Paysen, O. Kosch, L. Trahms, and F. Wiekhorst, "Temperature dependence in magnetic particle imaging," AIP Advances, vol. 8, no. 5, 2018, DOI: 10.1063/1.5004506

[2] D. Ilea, "Dan Ilea," 2011.

[3] W. Wu, X. Zhu, L. Quan, Y. Du, Z. Xiang, and X. Zhu, “Assisted synchronous reluctance motor considering," IEEE Trans. Appl. Supercond., vol. 28, no. 3, 2018, DOI: 10.1109/TASC.2017.2775584

[4] Iqbal Husein, "Minimization of torque ripple in SRM drives," IEEE Trans. Ind. Electron., vol. 49, no. 1, pp. 2839, 2002, DOI: $10.1109 / 41.982245$

[5] Thierry Lubin, "Contribution à la modélisation analytique des actionneurs électromécaniques," Université de Lorraine Ecole Doctorale "Informatique - Automatique - Electrotechnique - Electronique - Mathématiques" Département de Formation Doctorale "Electrotechnique - Electronique," 2016.

[6] E. Elhomdy, G. Li, J. Liu, S. Bukhari, and W. Cao, "Design and experimental verification of a 72/48 switched reluctance motor for low-speed direct-drive mining applications," Energies, vol. 11, no. 1, pp. 1-21, 2018, DOI: 10.3390/en11010192

[7] V. I. Goncharov, E. V. Kachalina, S. A. Korobkov, V. A. Kuzmichev and S. V. Shirinskii, "Electric machine type selection for high-speed megawatt-range generator," ARPN J. Eng. Appl. Sci., vol. 13, no. 1, pp. 370-376, 2018.

[8] X. Ma, G. Li, Z. Zhu, G. W. Jewell, and J. Green, "Investigation on synchronous reluctance machines with different rotor topologies and winding configurations," IET Electr. Power Appl., vol. 12, no. 1, pp. 45-53, 2017, DOI: 10.1049/iet-epa.2017.0199

[9] B. Multon, "Historique des machines électriques et plus particulièrement des machines à réluctance variable," To cite this version : HAL Id : hal-00674038, 2012

[10] M. Irfan, Machmud Effendy, Nur Alif, Lailis S, Ilham Pakaya, and Amrul Faruq, "Performance comparison of fuzzy logic and proportional-integral for an electronic load controller," International Journal of Power Electronics and Drive System (IJPEDS), vol. 8, no. 4, pp. 1886-1893, 2017, DOI: 10.11591/ijpeds.v8.i3.pp11761183

[11] Siti Khalidah Rahimi, Zarafi Ahmad, Erwan Sulaiman, Enwelum Mbadiwe I, Syed Muhammad Naufal Syed Othman, "Performance analysis of 12Slot with Various rotor pole numbers HE-FSM for HEV application," International Journal of Power Electronics and Drive System (IJPEDS), vol. 8, no. 4, pp. 1886-1893, 2017, DOI: 10.11591/ijpeds.v8.i4.pp1886-1893

[12] Emine Bostanci, Mehdi Moallem, Amir Parsapour and Babak Fahimi, "Opportunities and challenges of switched reluctance motor drives for electric propulsion: a comparative study," IEEE Trans. Appl. Supercond., vol. 3, no. 1, pp. 58-75, 2017, DOI: 10.1109/TTE.2017.2649883

[13] G. B. Mariani, "Machine synchrone à réluctance: modèles équivalents à réseau de réluctances pour la simulation et l'optimisation," Thesis, Université Grenoble Alpes, 2016.

[14] M. Sellami and S. Tounsi, "Control of axial flux DC motor with permanent magnet dedicated to electric traction," vol. 1, no. 1, pp. 44-48, 2015, DOI: 10.11648/j.ijecec.20150101.15

[15] A. Komatsuzaki, Y. Miura, and I. Miki, "Novel position estimation for switched reluctance motor based on space vector of phase inductance," 2008 International Conference on Electrical Machines and Systems, 2008, vol. 45, no. 1, pp. 2932-2937.

[16] J. Bai, J. Liu, M. Wang, P. Zheng, Y. Liu, H. Gao, et al., "Investigation of a less rare-earth permanent-magnet machine with the consequent pole rotor Investigation of a less rare-earth permanent-magnet machine with the consequent pole rotor," IEEE, vol. 8, no. 5, 2018, DOI: 10.1063/1.5006861

[17] M. Mitani, H. Goto, H. Guot, and O. Ichinokura, "Position sensorless direct torque control of SR motors," 2006 12th International Power Electronics and Motion Control Conference, pp. 1143-1148, DOI: 10.1109/EPEPEMC.2006.4778556

[18] A. Yao, M. Inoue, K. Tsukada, and K. Fujisaki, "Soft magnetic characteristics of laminated magnetic block cores assembled with a high Bs nanocrystalline alloy," vol. 8, no. 5, 2018, DOI: 10.1063/1.5006098

[19] YLavanya Dhanesn, P. Murugesan, A novel approach in scheduling of the real-time tasks in heterogeneous multicore processor with fuzzy logic technique for micro-grid power management," International Journal of Power Electronics and Drive System (IJPEDS), vol. 9, no. 1, pp. 80-88, March 2018, DOI: 10.11591/ijpeds.v9.i1.pp80-88 
[20] Mauro Di Nardo, Giovanni Lo Calzo, Michael Galea and Chris Gerada, "Design optimization of a high speed synchronous reluctance machine," IEEE Transactions on Industry Applications, vol. 54, no. 1, pp. 233-243, 2018, DOI: 10.1109/TIA.2017.2758759

[21] Flah A, Irfan Ahmed Khan, Agarwal A, Sbita L, and Marcelo G simoes, "Field-oriented control strategy for double-stator single-rotor and double-rotor single-stator permanent magnet machine: design and operation," Computers \& Electrical Engineering, vol. 90, 2021, DOI: 10.1016/j.compeleceng.2020.106953

[22] Flah A, Mahmoudi C. "A novel energy optimization approach for electrical vehicles in a smart city," Energies, vol. 12, no. 5, pp. 929, 2019, DOI: 10.3390/en12050929

[23] Flah Aymen, Majed Alowaidi, Mohit Bajaj, Naveen Kumar Sharma, Shailendra Mishra, and Sunil Kumar Sharma, "Electric vehicle model based on multiple recharge system and a particular traction motor conception," IEEE Access, vol. 9, DOI: 10.1109/ACCESS.2021.3068262

[24] Ahmad I, Flah A, Agarwal A, Kumar H. "Trapezoidal modulated direct matrix converter: for higher frequency AC/AC conversion," Indian J Pure Appl Phys, vol. 59, pp. 211-215, DOI:

[25] Flah A, Irfan Ahmed Khan, Agarwal A, Sbita L, and Marcelo G Simoes, "Field-oriented control strategy for double-stator single-rotor and double-rotor single-stator permanent magnet machine: design and operation," Computers \& Electrical Engineering, vol. 90, 2021, DOI: 10.1016/j.compeleceng.2020.106953 